\title{
Buckling Imperfection Sensitivity of Conical Sandwich Composite Structures for Launch-Vehicles
}

\author{
David W. Sleight ${ }^{1}$, Arunkumar Satyanarayana ${ }^{2}$, Yingyong Li ${ }^{2}$, and Marc R. Schultz ${ }^{3}$ \\ NASA Langley Research Center, Hampton, VA 23681, USA
}

\begin{abstract}
Structural stability can be an important consideration in the design of large composite shell structures and therefore it is important to understand the buckling response of such structures. It is well known that geometric imperfections can significantly influence the buckling response of such structures by causing the buckling loads to be significantly lower than the theoretical buckling load of a geometrically perfect shell structure. Results are presented of an analytical study on the buckling imperfection sensitivity of large-scale conical sandwich structures for launch vehicles. In particular, representative structures from the Space Launch System launch-vehicle development activities will be considered. The study considered composite sandwich conical structures with multiple sandwich core thicknesses and facesheet layups consisting of tape and fabric composite layups. The results of this analytical study indicate that there is conservatism in the NASA current buckling knockdown factor of 0.33 for conical shell structures. Therefore, it is suggested that the buckling response of composite sandwich cones be further investigated through buckling tests and analytical predictions to potentially revise the buckling design recommendations for conical composite structures.
\end{abstract}

\section{Nomenclature}

$\begin{array}{ll}\text { CTE } & =\text { Composite Technology for Exploration } \\ \text { FEA } & =\text { Finite-element analysis } \\ \text { FEM } & =\text { Finite-element model } \\ \text { GCD } & =\text { Game Changing Development } \\ \text { KDF } & =\text { Buckling knockdown factor } \\ \text { NESC } & =\text { NASA Engineering and Safety Center } \\ \text { PAF } & =\text { Payload Attach Fitting } \\ \text { SBKF } & =\text { Shell Buckling Knockdown Factor Project } \\ \text { SLS } & =\text { Space Launch System } \\ \text { STMD } & =\text { Space Technology and Mission Directorate } \\ \text { USA } & =\text { Universal Stage Adapter }\end{array}$

\section{Introduction}

\begin{abstract}
Composite shell structures are increasingly being considered and used for launch-vehicle structures. When properly designed, composite structures have the potential to have many benefits over traditional metallic structures, including lower mass, better fatigue resistance, lower part count, and reduced life-cycle cost. NASA is currently baselining sandwich structures for the elements of Space Launch System (SLS) now in development including the Universal Stage Adapter (USA) and the Payload Attach Fitting (PAF), which consist of conical shell structures. Structural stability can be an important consideration in the design of such large composite shell structures and therefore it is important to understand the buckling response of such structures. It is well known that geometric imperfections can significantly influence the buckling response by causing the buckling loads to be significantly lower than the theoretical buckling load of a geometrically perfect as-designed shell structure. To account for the imperfection sensitivity during design of thin-walled shell structures, the theoretical buckling load, which is typically
\end{abstract}

\footnotetext{
${ }^{1}$ Aerospace Engineer, Structural and Thermal Systems Branch, Hampton, VA 23681, 1 North Dryden Street, Mail Stop 431, AIAA Senior Member.

${ }^{2}$ Aerospace Engineer, Structural and Thermal Systems Branch, Hampton, VA 23681, 1 North Dryden Street, Mail Stop 431.

${ }^{3}$ Research Aerospace Engineer, Structural Mechanics and Concepts Branch, 8 West Taylor St, Mail Stop 190, AIAA Senior Member.
} 
determined by a linear bifurcation analysis, is multiplied by a design factor called a buckling knockdown factor (KDF) to generate a conservative design load. Therefore, the guidelines for determining these KDFs can be very important for the design of thin-walled shell structures. The most widely used source of KDFs by NASA and throughout world is a series of NASA buckling design monographs published in the 1960's. ${ }^{1-3}$ However, these document have not been updated in nearly fifty years, and composite shell structures were not included in the development of the design guidelines. Therefore, these guidelines may not be applicable to current aerospace shell structures constructed from composite materials, which have improved manufacturing processes and better tolerances. For the design of conical launch-vehicle structures, a universal KDF of 0.33 is recommended by NASA SP-8019. ${ }^{2}$ However, it is widely believed that this KDF value is overly conservative and can result in overweight designs.

In 2007, the NASA Engineering and Safety Center (NESC) established the Shell Buckling Knockdown Factor Project (SBKF) to revise the existing design factors and provide recommendations for buckling-critical metallic and composite shell structures. ${ }^{4}$ The SBKF project has also performed experimental validation for subcomponents, panels, and cylinders initially starting with metallic structures and is now doing the same for composite structures. In May 2016, The SBKF team, in a collaborative effort between SBKF and Northrop Grumman Corporation (NGC), successfully tested its first large-scale composite validation test article to buckling failure. ${ }^{5}$ The test article was an 8$\mathrm{ft}$-diameter honeycomb-core sandwich composite cylinder that was designated as CTA8.1. Pretest analyses were performed on the CTA8.1 by applying measured geometric imperfections from the test article to the analysis model in a stress-free way and then performing geometrically nonlinear analyses to predict realistic buckling loads. The pretest predictions for buckling failure compared very well with the test for both the buckling load and the prebuckling response. Several more large-scale composite sandwich cylinders are planned to be designed, fabricated, and tested by the SBKF project over the next several years to revise the KDFs for composite sandwich cylinder structures. ${ }^{6}$ At the present time, SBKF is not considering similar analytical or experimental validations to revise the KDFs for conical shell structures.

A similar recently concluded European Union project called the New Robust Design Guideline for Imperfection Sensitive Composite Launcher Structures (DESICOS) was conducted to develop less conservative design guidelines for imperfection sensitive thin-walled structures. ${ }^{7}$ The DESICOS project explored the use of the single perturbation load approach (SPLA), an analysis method wherein a radial load is used as an imperfection, for finding a lessconservative lower-bound estimate of the buckling load for design. The project has considered both composite cylinder and conical shell structures ${ }^{8-11}$ using the SPLA analysis method with experimental validation. For conical shell structures, the approach was demonstrated on conical shells less than one-meter tall.

The NASA Composite Technology for Exploration (CTE) project has the goal of advancing composite technologies that provide lightweight structures to support the Evolvable Mars Campaign. ${ }^{12}$ It also supports SLS payload adapters and fittings by maturing composite bonded joint technology and analytical tools to predict failure and enable risk reduction. As a part of this effort, the CTE team is conducting an analytical study on the buckling sensitivity of composite sandwich conical structures to geometric imperfections, similar to the some of the SBKF efforts.

Herein is discussed an investigation of the buckling imperfection sensitivity of large-scale conical sandwich structures for launch vehicles. In particular, representative structures from the SLS launch-vehicle development activities will be considered and include conical shell structures from the SLS USA and the SLS PAF. The current SLS USA design has a steep cone angle and the current SLS PAF design has a shallow cone angle. Studies on representative SLS USA and PAF conical structures at their full-height and one-half height are presented. Details for the geometry, design, and finite-element modeling parameters of the representative SLS USA and PAF conical structures are discussed in Sections II and III, respectively. Section IV provides the analysis methodology for the buckling imperfection sensitivity analytical studies. Finally, a discussion of the preliminary results from the buckling imperfection sensitivity studies for the representative SLS USA and PAF structures, and concluding remarks are given in Sections V and VI, respectively.

\section{Geometry and Design of Representative SLS and PAF Conical Structures}

The geometric parameters used to define the conical geometry are shown in Figure 1. The geometry of representative SLS USA and PAF conical structures were based on representative dimensions for the conical structures from the SLS. For each representative SLS conical structure, full-height and one-half-height (half-height) models were 
analyzed to investigate the effect of height on the buckling response. Table 1 provides the details of the geometry for the representative SLS USA and PAF full-height and one-half-height conical structures.

For the representative SLS USA and PAF conical structures, the designs for the buckling sensitivity study were all considered to be honeycomb-core sandwich composites with 3.1-pound-per-cubic-foot (pcf) Hexcel 5052, 1/8-in. cell size aluminum core ${ }^{13}$ with core thicknesses of 0.5, 1.0, and $1.5 \mathrm{in}$. and unidirectional IM7/8552 facesheets for tape $^{14}$ and fabric ${ }^{15}$ layups. For the tape layups a quasi-isotropic [+45/90/-45/0 $]_{s}$ layup and an axially stiff $[ \pm 45 / 90 / 0 / \overline{0}]_{s}$ layup were chosen with a ply thickness of 0.0054 in. For the fabric layup a [45/0/0/0/0/45 $]_{\mathrm{T}}$ layup was chosen with a fabric ply thickness of 0.00787 in. These ply orientations are with respect to the shell surface with the zero-degree direction mapped to the surface from the axial coordinate, the 90-degree plies were oriented with the circumferential coordinate, and the third coordinate was the shell normal.

\section{Finite-Element Model Parameters of Representative SLS and PAF Conical Structures}

The general-purpose finite-element code, Abaqus Standard 6.14 ${ }^{16}$, was used to perform the finite-element analysis (FEA). The finite-element models (FEM) for the representative SLS USA and PAF conical structures used 360 elements around the circumference. The number of elements used in the axial direction was chosen to give the elements an aspect ratio of nearly 1:1 at the midheight of the conical structures. The number of elements for each of the models is shown in Table 1. The S4R four-node, quadrilateral shell element with reduced integration and a largestrain formulation was used in the analyses. The boundary and loading conditions were applied to center nodes at the top and bottom of the conical structures that were attached to the nodes along the circumference with multi-point constraints (MPCs). The bottom center node was fixed in all translational and rotational degrees of freedom in a cylindrical coordinate system and the top of the structure was fixed in the radial and circumferential translational degrees of freedom as well as all rotational directions of freedom in a cylindrical coordinate system. The load was applied as an axially compressive displacement at the top of the structure at a center node. The FEM for the representative SLS USA full-height model is shown in Figure 2. A series of linear bifurcation and nonlinear buckling analyses were performed for each considered structure. For the nonlinear buckling analyses, a combination nonlinear static and nonlinear transient analysis was performed using displacement control. The nonlinear static analysis simulated loading up to $80 \%$ of the predicted linear bifurcation buckling load. The nonlinear transient analysis continued the loading simulation from this point through buckling and into the postbuckling range. The predicted buckling load was determined by the peak prior to a load drop in a plotted load-deflection curve.

\section{Analysis Methodology for Buckling Imperfection Sensitivity Study}

For the representative SLS USA and PAF structures, the buckling imperfection sensitivity would ideally be explored using by including the analyses characteristic imperfections that are typical of large-scale composite conical shell structures. However, such characteristic imperfections from large-scale composite conical shell structures were not available for the present study. Therefore, to investigate the imperfection sensitivity of the representative SLS USA and PAF structures, the measured radial imperfection (deviation of the as-built geometry from a best-fit cylinder) of the previously mentioned CTA8.1 was used in the study (Figure 3). The measured imperfection shape from the CTA8.1 was scaled (in both length and circumference) to the geometry of the considered structures, and the amplitude of the measured radial imperfection was varied. The amplitudes considered were zero (no imperfection) and linearly scaled amplitudes of 1x, 2x, 5x, and 10x the CTA8.1 as-measured imperfections. The measured CTA8.1 radial imperfections ranged from -0.12 to +0.08 in. and for the radial imperfections scaled by $10 \mathrm{x}$ ranged from -1.20 to +0.80 in. The imperfections applied to the representative full-height SLS USA conical structure are shown in Figure 4 for a scaled 10x imperfection. The scaled imperfection was applied in a stress-free manner to the finite-element models of the representative SLS USA and PAF conical structures, and geometrically nonlinear static and nonlinear transient dynamic finite-element analyses were performed to determine the nonlinear buckling responses and loads. For each considered conical structure, a linear bifurcation buckling analysis of the perfect geometry and geometrically nonlinear transient dynamic analyses for each of the imperfection amplitudes was performed. For all analyses performed, global buckling was the only failure mode considered. No additional failures attributed to facesheet strength or honeycomb sandwich failure modes were considered, but should be in the actual design of a launch vehicle structure.

\section{Buckling Imperfection Sensitivity Study Results}

Results of the buckling imperfection sensitivity studies for the representative SLS USA and PAF conical structures with core thicknesses of 0.5, 1.0, and $1.5 \mathrm{in}$. and facesheets for tape and fabric layups are discussed in this section. For both the representative SLS USA and PAF conical structures, typical analytical results including load-vs.-end-

American Institute of Aeronautics and Astronautics 
shortening curves and radial-deformation plots at the predicted buckling load are presented for the models with $1.0 \mathrm{in}$. sandwich cores and the quasi-isotropic facesheets. Normalized buckling loads (defined as the nonlinear buckling load divided by the linear bifurcation buckling load of the geometrically perfect models) as well as buckling load vs. peakto-peak imperfection magnitude are presented for all analytical results for all sandwich thicknesses and facesheets.

\section{A. Representative SLS USA Conical Structures}

Typical load-vs.-end-shortening results from the nonlinear analyses for the representative SLS USA full-height and half-height conical structures are shown in Figure 5 and Figure 6, respectively for a core thickness of 1.0 in. with a quasi-isotropic layup. The buckling loads for the nonlinear analyses are compared to the linear bifurcation buckling load of the geometrically perfect model designated as $\mathrm{P}_{\mathrm{bif}}$. For both the representative SLS USA full-height and halfheight conical structures, the nonlinear buckling analysis results for all imperfection amplitudes are lower than the linear bifurcation buckling load. These results also indicate that, for the full-height structure, the load suddenly drops significantly when buckling occurs for the $0 \mathrm{x}, 1 \mathrm{x}, 2 \mathrm{x}$, and $5 \mathrm{x}$ imperfection amplitudes; for the 10x imperfection amplitude, the load shows a smaller sudden load drop at buckling. For the half-height structure, the load suddenly drops significantly for imperfections with amplitudes of $0 \mathrm{x}, 1 \mathrm{x}$, and $2 \mathrm{x}$. For the other imperfection amplitudes (5x and 10x), the load-end-shortening curves show significant softening prior to relatively small load drops. A summary of the buckling loads for the two different-height USA structures is given in Table 2. The results indicate that the normalized buckling loads for the geometrically perfect (0x imperfection) full-height and half-height structures are 0.88 and 0.85 , respectively. The normalized buckling loads for imperfection amplitudes of 10x for the full-height and half-height structures are 0.63 and 0.73 , respectively. For all imperfection amplitudes considered for the structures with a 1.0 in. core and quasi-isotropic facesheets, the normalized buckling loads were all larger than 0.60 and significantly higher than the current SP-8019 recommendation of 0.33 . This study also revealed that the predicted buckling loads for the half-height structures were similar to those of the full-height structures. Radial deformations at the predicted buckling load for the analyses with various levels of imperfection amplitudes for the representative SLS USA full-height and half-height structures are shown in Figure 7 and Figure 8, respectively. The radial deformation at the buckling load changes as the imperfection amplitudes are increased. As the imperfection amplitudes are increased the buckling patterns are dominated by a single large inward dimple that is increases in magnitude.

The normalized buckling loads for the representative SLS USA full-height and half-height conical structures for all sandwich core thicknesses (0.5, 1.0, and 1.5 in.) and all facesheet layups (quasi-isotropic tape, axially stiff tape, and fabric) are presented graphically in Figures 9 and 10, respectively. The results indicate that, in general, there is little change in normalized buckling loads for imperfection amplitudes of $1 \mathrm{x}$ and $2 \mathrm{x}$ when compared with the perfect conical structures. Also, the majority of the structures with the various levels of imperfection amplitudes have normalized buckling loads above 0.60; the only exceptions are the two full-height SLS USA models with a 0.5-in. core with an imperfection magnitude of 10x for the quasi-isotropic and axially stiff tape facesheet layups. Figure 11 shows plots of the buckling load vs. peak-to-peak imperfection magnitude for (a) the full-height and (b) the half-height representative SLS USA conical structures for all sandwich core thicknesses and facesheet layups. As expected, the buckling loads are the lowest for the 0.5-in. sandwich core and the highest for the 1.5-in. sandwich core for all imperfection magnitudes. The results also showed as expected that the quasi-isotropic facesheets had the lowest buckling loads because the quasi-isotropic facesheet thickness was the thinnest compared to all facesheets considered. Lastly, the study also showed that the buckling loads for the half-height conical structures were nearly the same as the full-height conical structures.

\section{B. Representative SLS PAF Conical Structures}

Typical load-vs.-end-shortening results from the nonlinear analyses for the representative SLS PAF full-height and half-height conical structures are shown in Figure 12 and Figure 13, respectively for a core thickness of 1.0-in. with a quasi-isotropic layup. The buckling loads for the nonlinear analyses are again compared to the linear bifurcation buckling load of the geometrically perfect model. These results indicate that for the full-height structure the prebuckling responses show softening prior to buckling and the load suddenly drops significantly when buckling occurs for all imperfection amplitudes. For the half-height structure, the prebuckling responses also show softening for all imperfection amplitudes and the load suddenly drops for all imperfection amplitudes. A summary of the buckling loads for the two different-height PAF structures with the quasi-isotropic facesheet and 1-in. core is given in Table 3. The results indicate that the normalized buckling loads for these geometrically perfect (0x imperfection) fullheight and half-height structures are 0.84 and 0.85 , respectively. The normalized buckling loads for 10x imperfection amplitudes for these full-height and half-height structures are 0.75 and 0.77 , respectively. For all imperfection amplitudes considered for the structures with a 1.0-in. core and quasi-isotropic facesheets, the normalized buckling 
loads were all larger than 0.60 , which again is significantly higher than the current SP-8019 recommendation of a 0.33 KDF. As with the previous study for the representative SLS USA structures, the results of the representative SLS PAF structures also revealed that the buckling loads for the half-height structures were similar to those of the full-height structures. Radial deformations at the predicted buckling load for the analyses with various levels of imperfection amplitudes for the representative SLS PAF full-height and half-height models with the quasi-isotropic facesheet and 1-in. core are shown in Figure 14 and Figure 15, respectively. The radial buckling-load deformation for the geometrically perfect (0x) full-height structure has an accordion-like buckling mode shape. The full-height structures with $1 x, 2 x, 5 x$, and 10x imperfection amplitudes also have an accordion-like buckling-load radial deformations at the top of the conical section, but the radial deformations in the lower section of the conical structures are influenced by the applied imperfections, which are larger in magnitude for larger imperfection amplitudes. For the half-height models, the 0x imperfection amplitude structure shows an accordion-like buckling-load radial deformations, but for imperfection amplitudes of $1 \mathrm{x}$ and larger the buckling-load radial-deformation patterns are dominated by an inward dimple.

The normalized buckling loads for the representative SLS PAF full-height and half-height conical structures for all sandwich core thicknesses $(0.5,1.0$, and 1.5 in.) and all facesheet layups (quasi-isotropic tape, axially stiff tape, and fabric) are shown graphically in Figures 16 and 17, respectively. The results again indicate that, in general, there is little change in normalized buckling loads for imperfection amplitudes of $1 \mathrm{x}$ and $2 \mathrm{x}$ when compared with the perfect conical structures. Also, the full-height and half-height representative SLS PAF structures have normalized buckling loads above 0.60 for all imperfection amplitudes considered. Figure 18 shows plots of the buckling load vs. peak-topeak imperfection magnitude for (a) the full-height and (b) the half-height representative SLS PAF conical structures for all sandwich core thicknesses and facesheet layups. As expected, the buckling loads are the lowest for the 0.5-in. sandwich core and the highest for the 1.5-in. sandwich core for all imperfection magnitudes. The results also showed as expected that the quasi-isotropic facesheets had the lowest buckling loads because the quasi-isotropic facesheet thickness was the thinnest compared to all facesheets considered. Lastly, the study also showed that the buckling loads for the half-height conical structures were nearly the same as the full-height conical structures.

\section{Concluding Remarks}

The current design recommendations for large-scale composite sandwich conical shell structures for launch vehicles use very conservative buckling knockdown factors (KDFs) for design. Results were presented from a numerical buckling imperfection sensitivity study for representative Space Launch System (SLS) conical composite sandwich shell structures. In this study, the shells representative of the Universal Stage Adapter (USA) and the Payload Attach Fitting (PAF) at full-height and one-half height were considered. The imperfection sensitivity was explored by considering imperfection amplitudes ranging $0 \mathrm{x}$ to $10 \mathrm{x}$ of the measured radial imperfections from a recently tested large-scale composite cylinder. The measured imperfection shape from this test article was scaled (in both length and circumference) to the geometry of the considered conical structures. The study considered composite sandwich structures with sandwich core thicknesses (0.5, 1.0, and 1.5-in.) and facesheet layups consisting of tape (quasiisotropic and axially stiff) and fabric composite layups. The results of this study showed that all the normalized buckling loads are all greater than 0.50, even for imperfection amplitudes with peak-to-peak amplitudes as high as 1.2 in. In fact, all of the normalized buckling loads except two were larger than 0.60 . The results of this study indicate that there is significant conservatism in the NASA current KDF recommendation of 0.33 for all conical shell structures. Therefore, it is expected that revising the buckling design recommendations for conical composite shell structures (based on numerical predictions validated with conical buckling test data) has the potential to reduce the acreage areal mass for conical launch-vehicle structures.

\section{Acknowledgments}

This work was conducted as part of the Composite Technology for Exploration Project funded by the Space Technology and Mission Directorate (STMD) Game Changing Development (GCD) Program and the Space Launch System (SLS) Program.

American Institute of Aeronautics and Astronautics 


\section{References}

${ }^{1}$ Anonymous, "Buckling of Thin-Walled Circular Cylinders,” NASA Space Vehicle Design Criteria, NASA SP-8007, September 1965 (Revised 1968).

${ }^{2}$ Anonymous, “Buckling of Thin-Walled Truncated Cones,” NASA Space Vehicle Design Criteria, NASA SP-8019, September 1968.

${ }^{3}$ Anonymous, "Buckling of Thin-Walled Doubly Curved Shells,” NASA Space Vehicle Design Criteria, NASA SP-8032, August 1969.

${ }^{4}$ Hilburger M.W., "Developing the Next Generation Shell Buckling Design Factors and Technologies," Proceedings of the 53rd AIAA/ASME/ASCE/AHS/ASC Structures, Structural Dynamics and Materials Conference, AIAA paper no. 2012-1686, Honolulu, HI, April 2012.

${ }^{5}$ Schultz, M.R., Sleight, D.L., Gardner, N.W., Rudd, M.T., Hilburger, M.W., Palm, T.E., and Oldfield, N.J., "Test and Analysis of a Buckling-Critical Large-Scale Sandwich Composite Cylinder," Proceedings of the 58 ${ }^{\text {th }}$ AIAA/ASME/ASCE/AHS/ASC Structures, Structural Dynamics \& Materials Conference, Orlando, FL, January 2018 (submitted for publication).

${ }^{6}$ Przekop, A., Schultz, M.R., and Hilburger, M.W., "Design of Buckling-Critical Large-Scale Sandwich Composite Cylinder Test Articles,” Proceedings of the 58 ${ }^{\text {th }}$ AIAA/ASME/ASCE/AHS/ASC Structures, Structural Dynamics \& Materials Conference, Orlando, FL, January 2018 (submitted for publication).

${ }^{7}$ DESICOS. [Online].Available: 〈http://www.desicos.eu〉.

${ }^{8}$ Khakimova R., Castro S.G, Arbelo M.A., Degenhardt R., Rohwer Z., Zimmermann C., Quappen G., and Hinsch S., "Studies of Imperfection Sensitive Conical Composite Structures,” Proceedings of the 21st International Annual Conference on Composites Engineering (ICCE 21), January 2013.

${ }^{9}$ Di Pasqua M.F, Khakimova R, Arbelo M.A., Degenhardt R., Castro S.G., and Riccio A., "The Influence of Geometrical Parameters on the Buckling Behavior of Conical Shell by the Single Perturbation Load Approach,” Applied Composite Materials, Vol. 22, Issue 4, August 2015, pp 405-422.

${ }^{10}$ Khakimova R., Warren C.J, Zimmermann R., Castro S.G., Arbelo M.A, and Degenhardt R., “The Single Perturbation Load Approach Applied to Imperfection Sensitive Conical Composite Structures,” Thin-Walled Structures, Vol. 84: November 2014, pp. 369-377,

${ }^{11}$ Khakimova R., Zimmermann R., Wilckens D., Rohwer K., and Degenhardt R., "Buckling of axially compressed CFRP truncated cones with additional lateral load: Experimental and numerical investigation,” Composite Structures, Vol. 157, December 2016, pp 436-447.

${ }^{12}$ Craig, D.A, Herrmann, N.B., and Troutman, P.A., “The Evolvable Mars Campaign - Study Status,” Proceedings of the 2015 IEEE Aerospace Conference, Big Sky, MT, March 2015, pp 1-14.

${ }^{13}$ Anonymous, "HexWeb ${ }^{\mathrm{TM}}$ Honeycomb Attributes and Properties," Hexcel Corporation, 1999.

${ }^{14}$ Marlett, K., Ng, Y., and Tomblin, J., "Hexcel 8552 IM7 Unidirectional Prepreg 190 gsm \& 35\% RC Qualification Material Property Data Report”, CAM-RP-2009-015 Rev A, April 23, 2011 report for IM7/8552 Unidirectional tape.

${ }^{15}$ Krueger, R., and Ratcliffe, J., “Analysis of Composite Panel-Stiffener Debonding Using a Shell/3D Modeling Technique”, NASA/CR-2007-214879, NIA Report No. 2007-07, June, 2007.

${ }^{16}$ Abaqus, Software Package, Ver. 6.14. Dassault Systèmes, Waltham, MA, 2014.

American Institute of Aeronautics and Astronautics 
Table 1. Geometrical and model parameters of representative SLS conical structures.

\begin{tabular}{ccccc}
\hline Dimensions & $\begin{array}{c}\text { SLS USA, } \\
\text { Full Height }\end{array}$ & $\begin{array}{c}\text { SLS USA, } \\
\text { Half Height }\end{array}$ & $\begin{array}{c}\text { SLS PAF, } \\
\text { Full Height }\end{array}$ & $\begin{array}{c}\text { SLS PAF, } \\
\text { Half Height }\end{array}$ \\
\hline Top diameter, $D_{\text {top }}$ & 229.2 in & 280.0 in & 62.0 in & 196.5 in \\
Bottom diameter, $D_{\text {bot }}$ & 331.0 in & 331.0 in & 331.0 in & 331.0 in \\
Cone angle, $\alpha$ & $75^{\circ}$ & $75^{\circ}$ & $45^{\circ}$ & $45^{\circ}$ \\
Height, $H$ & 190.0 in & 95.0 in & 134.5 in & 67.3 in \\
Number of Elements & 28,800 & 13,320 & 40,320 & 14,760 \\
\hline
\end{tabular}

Table 2. Summary of buckling loads for representative SLS USA conical structures with a 1-in. sandwich core and quasi-isotropic facesheet layup.

\begin{tabular}{|c|c|c|c|c|}
\hline \multirow[b]{2}{*}{$\begin{array}{l}\text { Imperfection } \\
\text { Scale Factor }\end{array}$} & \multicolumn{2}{|c|}{ Full-Height Model } & \multicolumn{2}{|c|}{ Half-Height Model } \\
\hline & Buckling Load (lbf) & $\begin{array}{c}\text { Normalized } \\
\text { Buckling Load }\end{array}$ & Buckling Load (lbf) & $\begin{array}{c}\text { Normalized } \\
\text { Buckling Load }\end{array}$ \\
\hline $0 \mathrm{x}$ & $3.622 \mathrm{E}+6$ & 0.88 & $3.515 \mathrm{E}+6$ & 0.85 \\
\hline $1 \mathrm{x}$ & $3.552 E+6$ & 0.86 & $3.406 \mathrm{E}+6$ & 0.82 \\
\hline $2 \mathrm{x}$ & $3.522 E+6$ & 0.85 & $3.336 \mathrm{E}+6$ & 0.80 \\
\hline $5 x$ & $3.195 E+6$ & 0.77 & $3.186 \mathrm{E}+6$ & 0.77 \\
\hline $10 x$ & $2.615 E+6$ & 0.63 & $3.047 \mathrm{E}+6$ & 0.73 \\
\hline $\begin{array}{c}\text { 0x - Linear } \\
\text { Bifurcation Analysis }\end{array}$ & $4.126 E+6$ & NA & $4.152 \mathrm{E}+6$ & NA \\
\hline
\end{tabular}

Table 3. Summary of buckling loads for representative SLS USA conical structures with a 1-in. sandwich core and quasi-isotropic facesheet layup.

\begin{tabular}{|c|c|c|c|c|}
\hline \multirow[b]{2}{*}{$\begin{array}{l}\text { Imperfection } \\
\text { Scale Factor }\end{array}$} & \multicolumn{2}{|c|}{ Full-Height Model } & \multicolumn{2}{|c|}{ Half-Height Model } \\
\hline & Buckling Load (lbf) & $\begin{array}{c}\text { Normalized } \\
\text { Buckling Load }\end{array}$ & Buckling Load (lbf) & $\begin{array}{c}\text { Normalized } \\
\text { Buckling Load }\end{array}$ \\
\hline $0 \mathrm{x}$ & $1.766 \mathrm{E}+06$ & 0.83 & $1.894 \mathrm{E}+06$ & 0.85 \\
\hline $1 \mathrm{x}$ & $1.747 \mathrm{E}+06$ & 0.83 & $1.857 \mathrm{E}+06$ & 0.83 \\
\hline $2 \mathrm{x}$ & $1.737 \mathrm{E}+06$ & 0.82 & $1.833 \mathrm{E}+06$ & 0.82 \\
\hline $5 x$ & $1.694 \mathrm{E}+06$ & 0.80 & $1.762 \mathrm{E}+06$ & 0.79 \\
\hline $10 x$ & $1.573 \mathrm{E}+06$ & 0.74 & $1.715 \mathrm{E}+06$ & 0.77 \\
\hline $\begin{array}{l}\text { 0x - Linear } \\
\text { Bifurcation Analysis }\end{array}$ & $2.113 \mathrm{E}+06$ & NA & $2.233 \mathrm{E}+06$ & NA \\
\hline
\end{tabular}




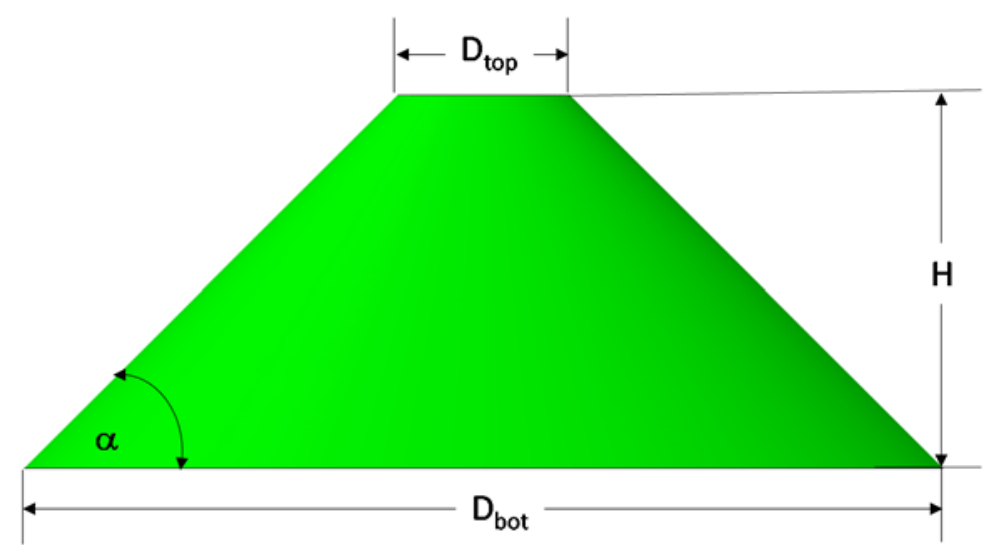

Figure 1. Geometrical dimensions of SLS conical structures.

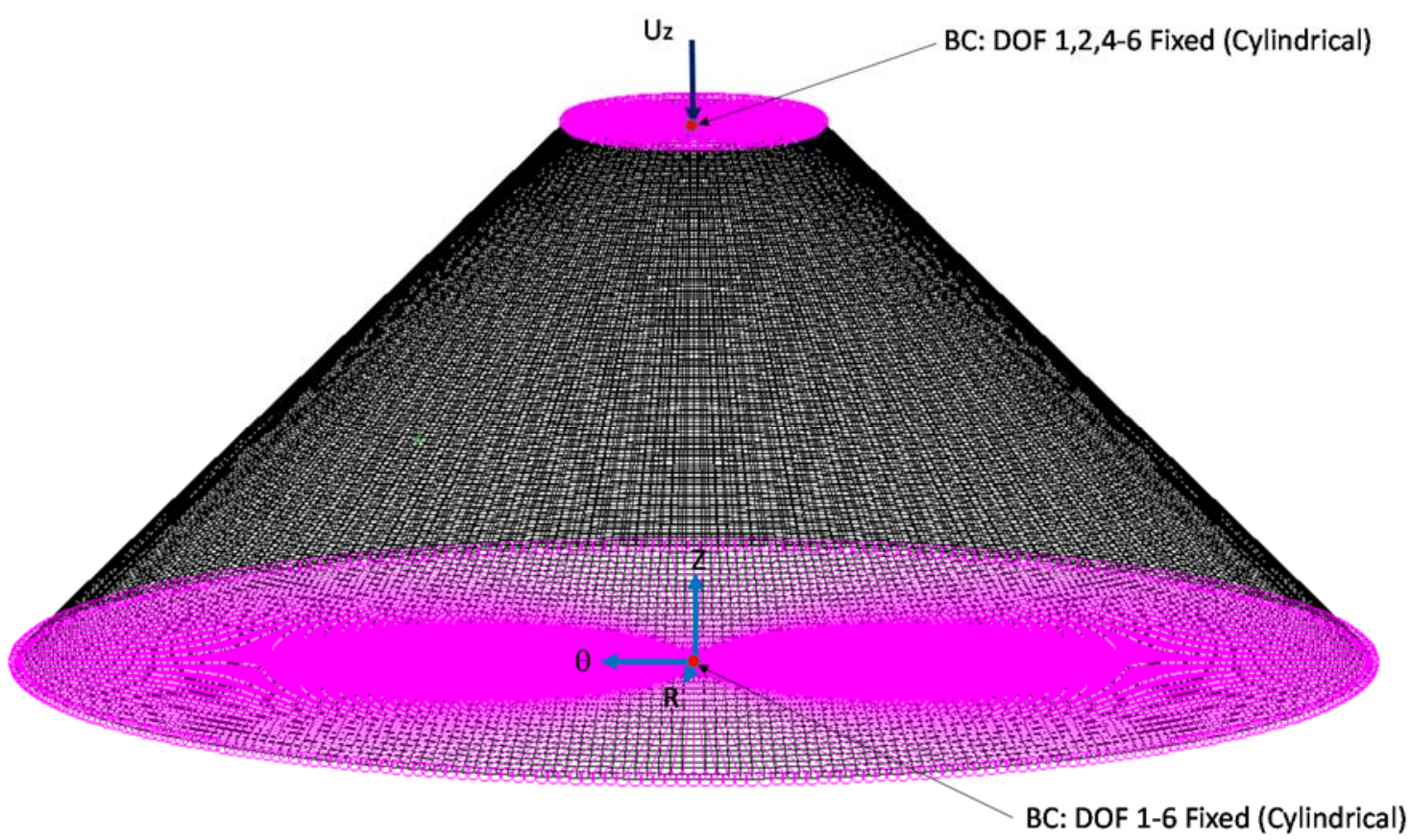

Figure 2. Finite-element model with loading and boundary conditions. 


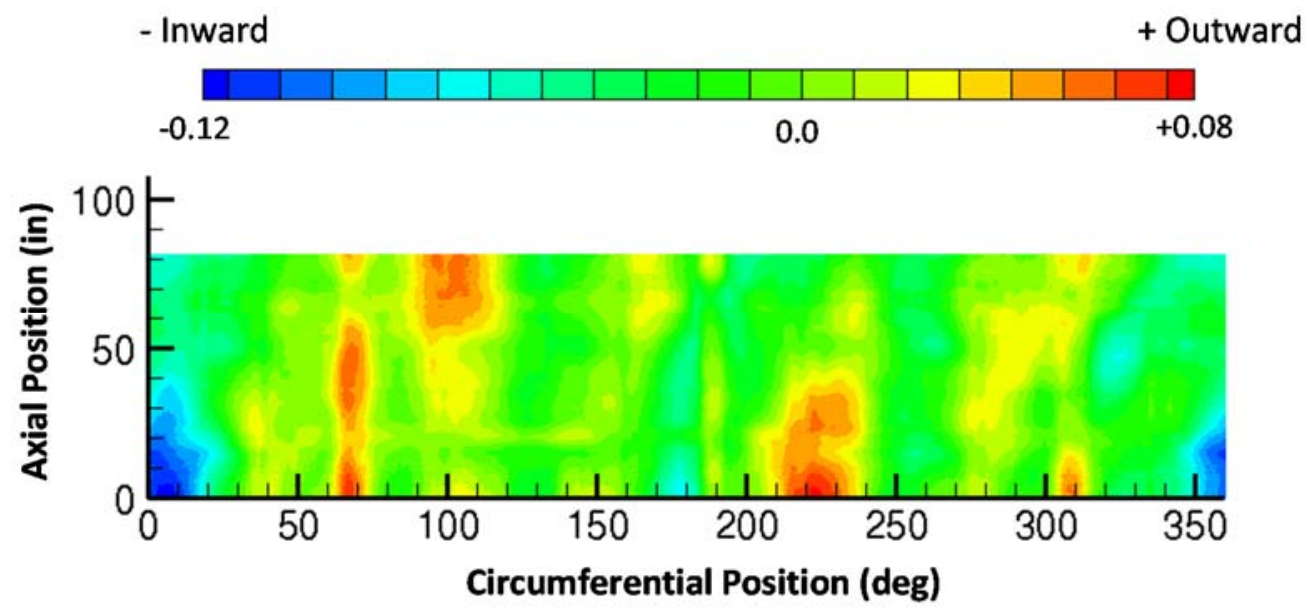

Figure 3. Measured midsurface radial imperfections from CTA8.1 cylinder.

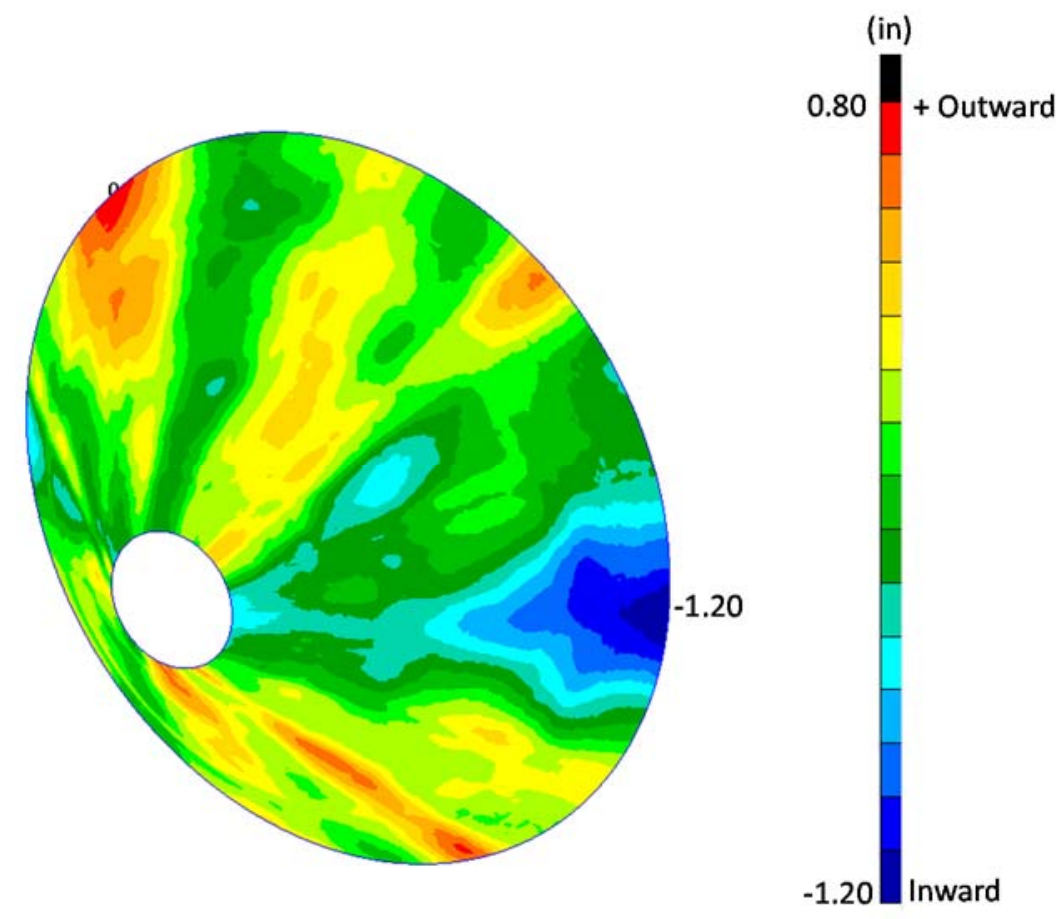

Figure 4. Scaled 10x radial imperfection on the representative full-height SLS USA conical structure. 


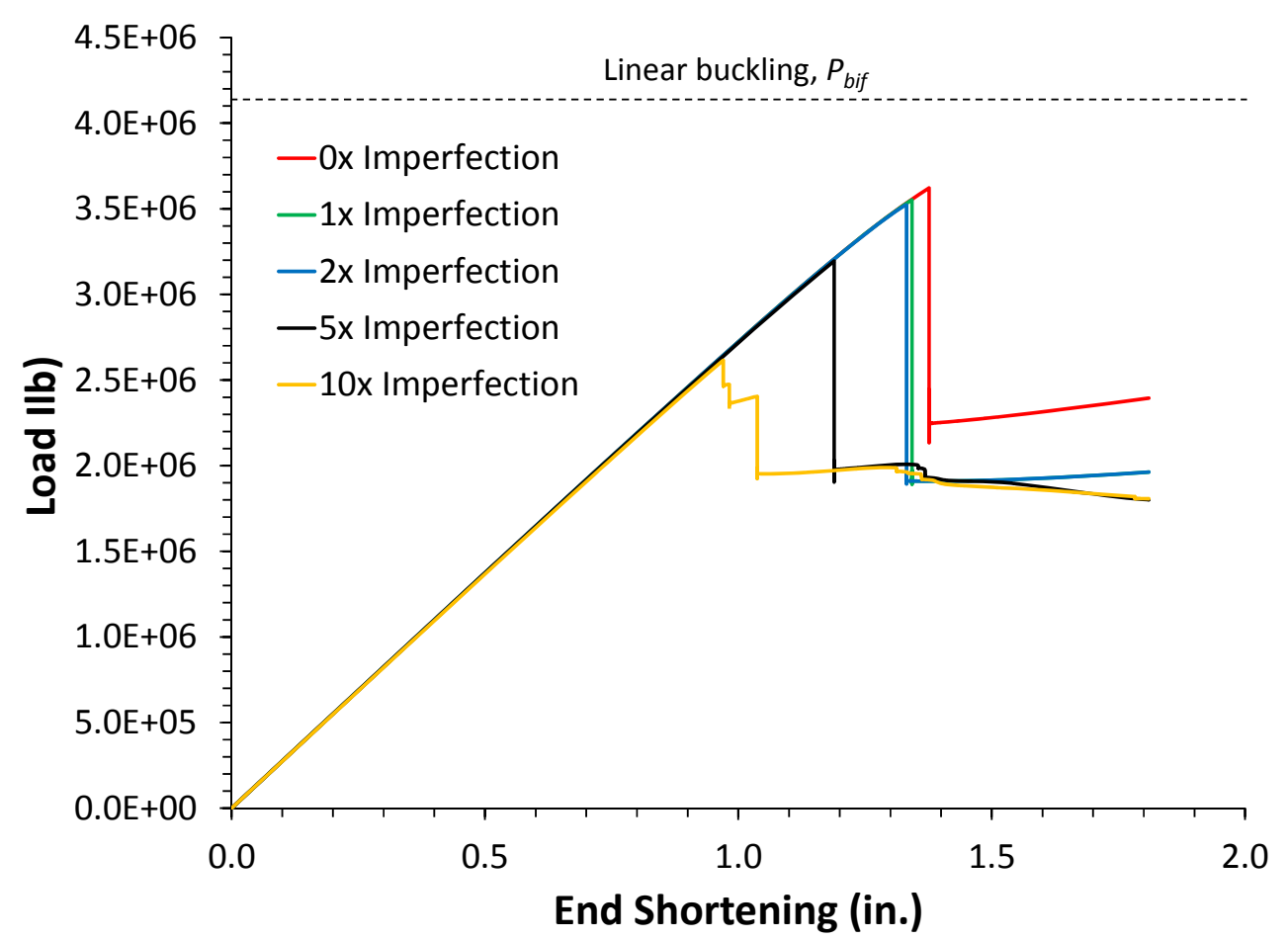

Figure 5. Buckling imperfection sensitivity study for representative full-height SLS USA conical structures with 1.0-in. sandwich core and quasi-isotropic facesheet layup.

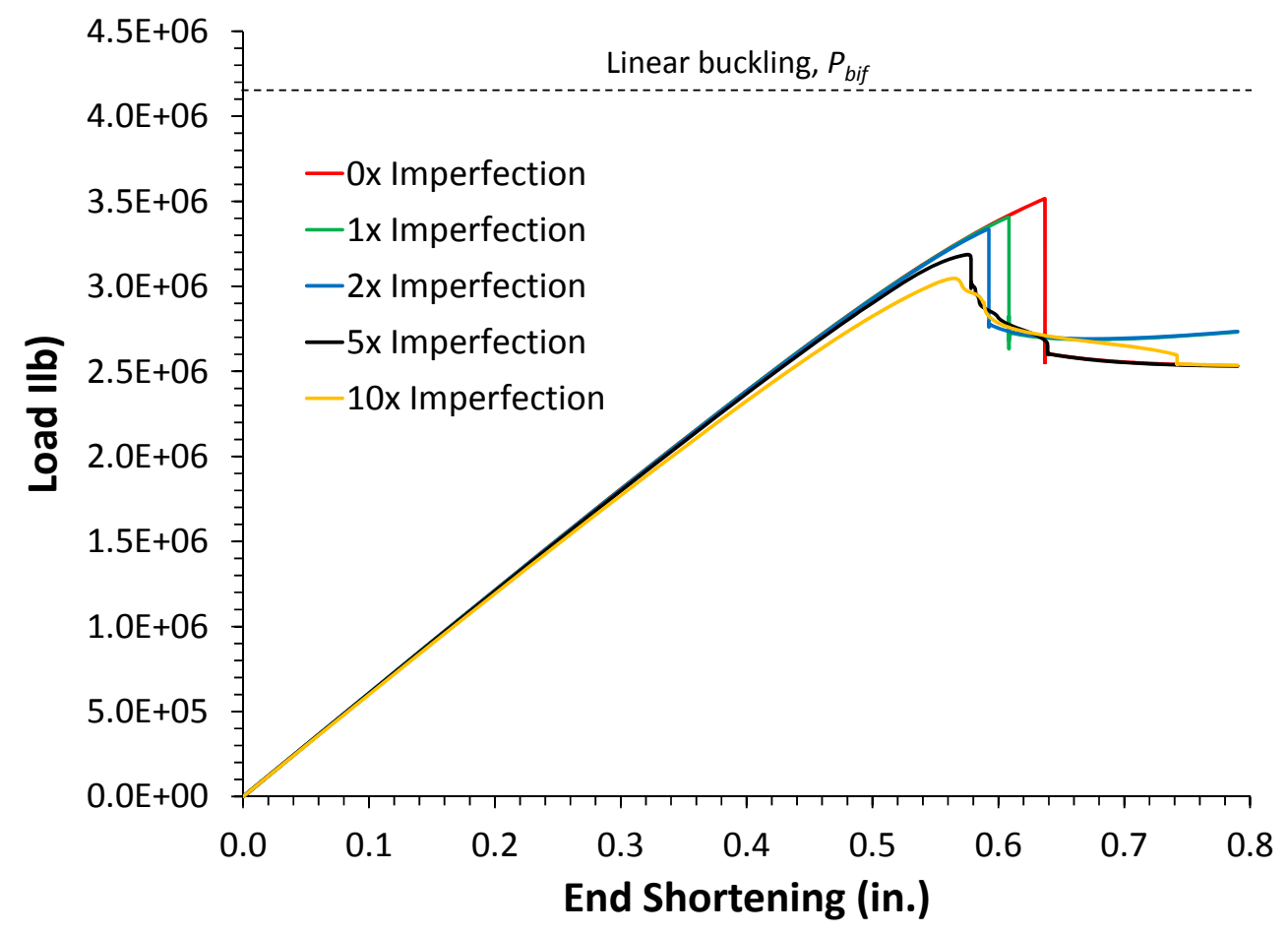

Figure 6. Buckling imperfection sensitivity study for representative half-height SLS USA conical structures with 1.0-in. sandwich core and quasi-isotropic facesheet layup. 

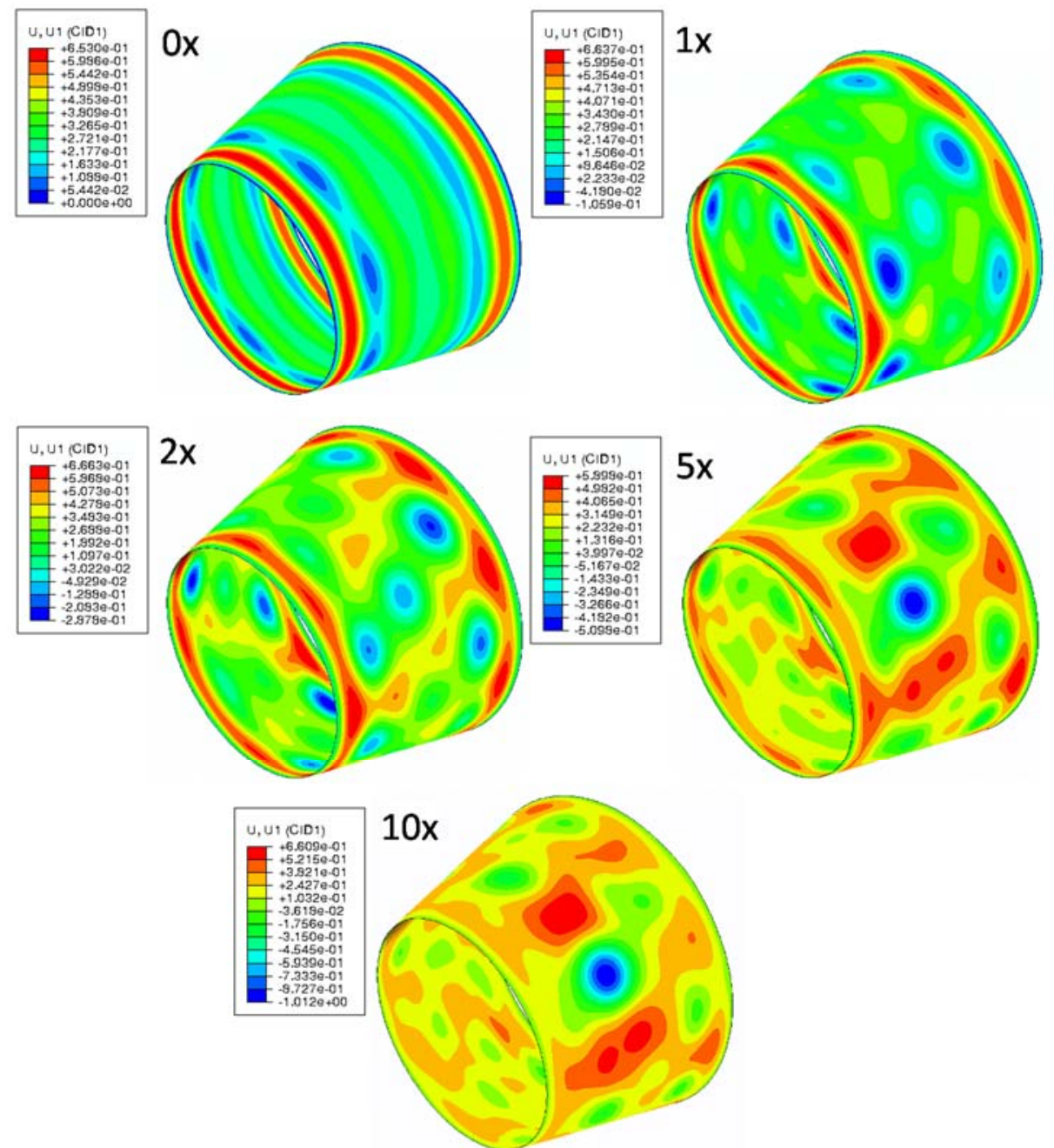

Figure 7. Radial deformation of representative SLS USA full-height conical structures for various imperfection amplitudes with 1.0-in. sandwich core and quasi-isotropic facesheet layup. 

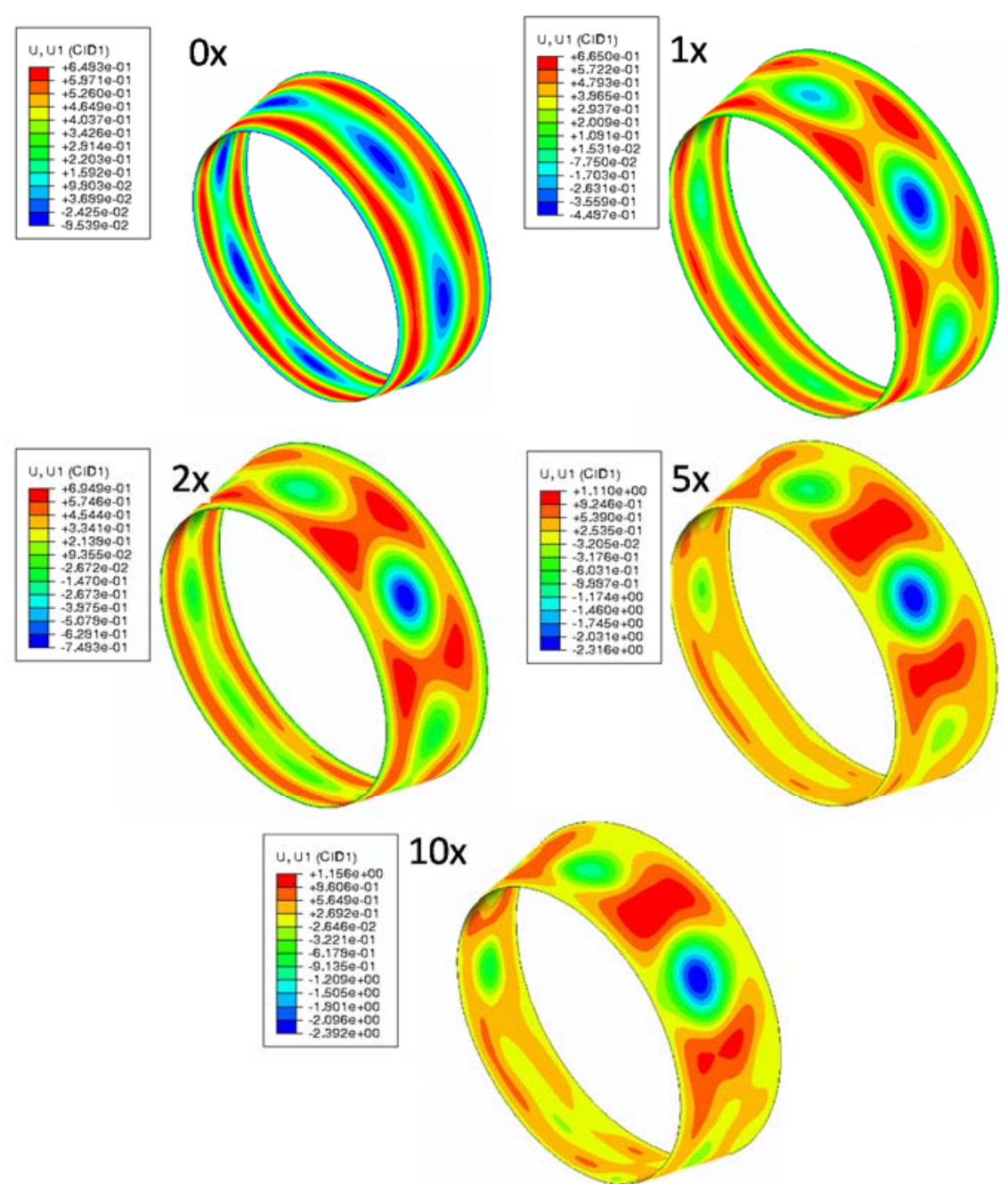

Figure 8. Radial deformation of representative SLS USA half-height conical structures for various imperfection amplitudes with 1.0-in. sandwich core and quasi-isotropic facesheet layup. 

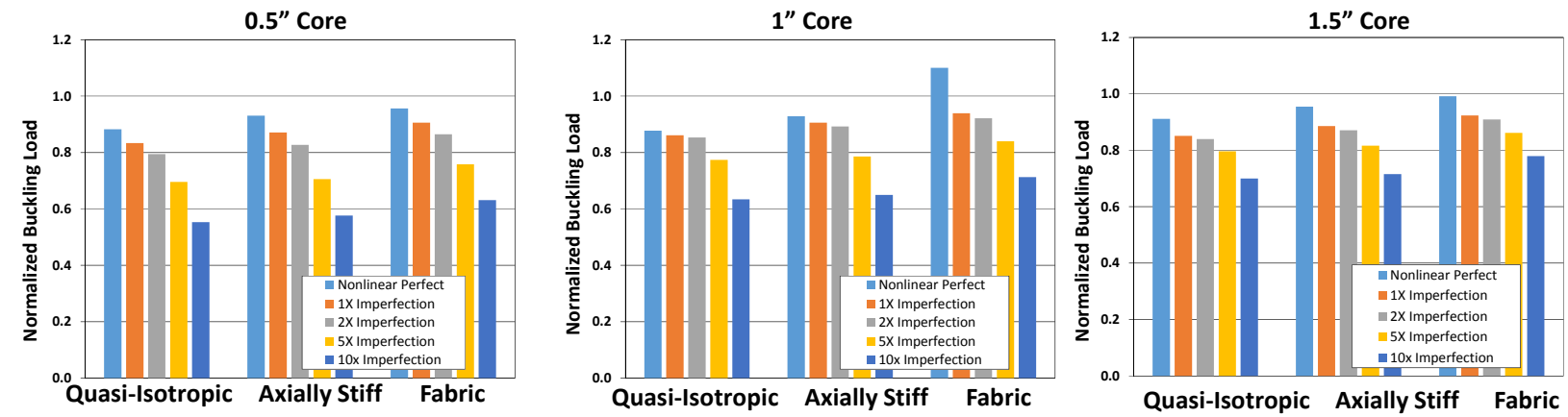

Figure 9. Normalized buckling loads of representative SLS USA full-height conical structures for all sandwich core thicknesses (0.5, 1.0, and $1.5 \mathrm{in}$.) and facesheet layups (quasi-isotropic tape, axially stiff tape, and fabric) for various imperfection amplitudes.
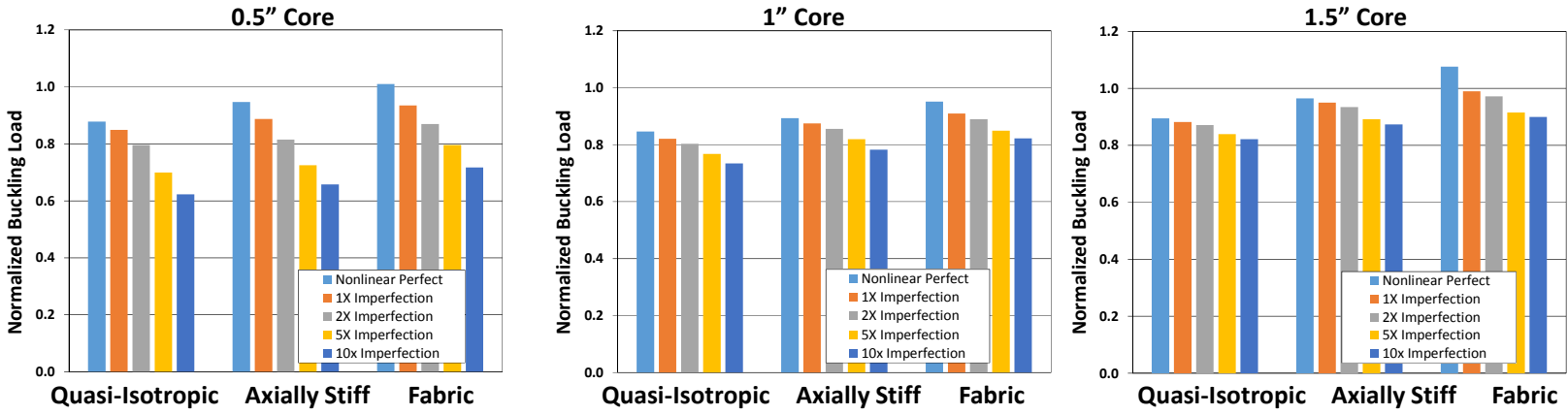

Figure 10. Normalized buckling loads of representative SLS USA half-height conical structures for all sandwich core thicknesses $(0.5,1.0$, and 1.5 in.) and facesheet layups (quasi-isotropic tape, axially stiff tape, and fabric) for various imperfection amplitudes.

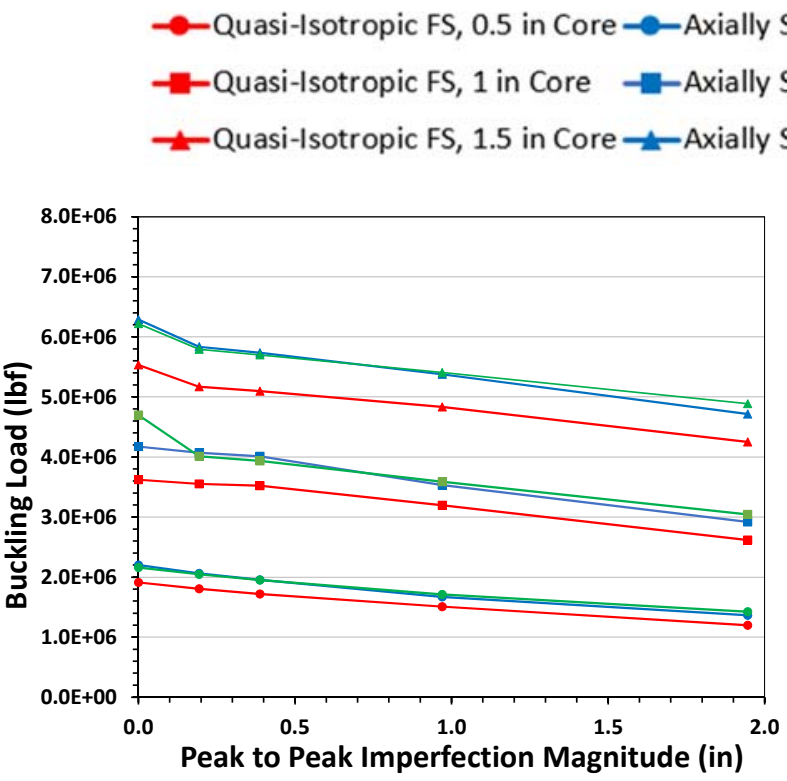

(a) Full-Height
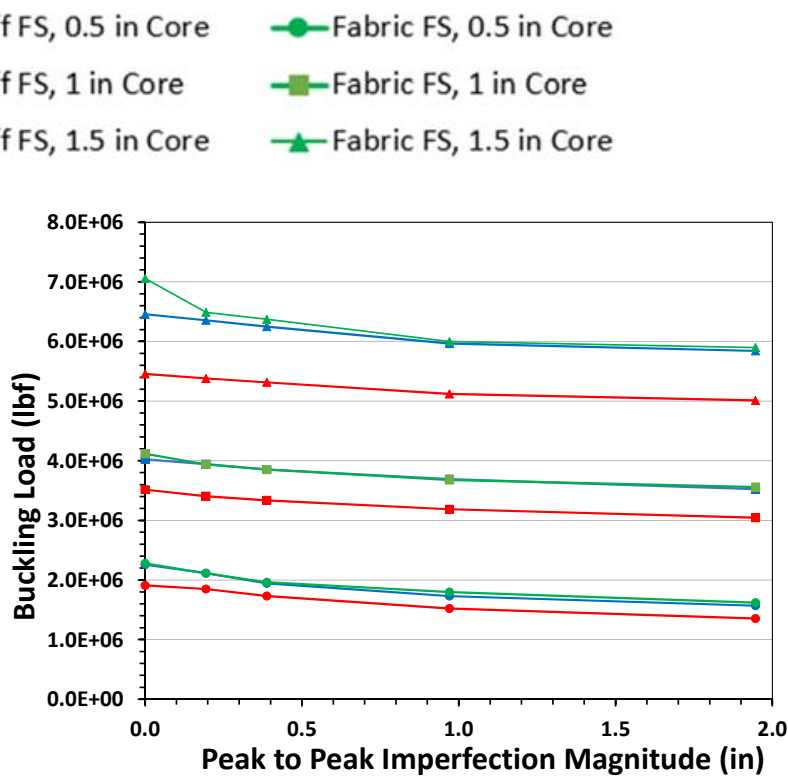

(b) Half-Height

Figure 11. Buckling load vs. peak-to-peak imperfection magnitude of representative SLS USA full-height and half-height conical structures for all sandwich core thicknesses $(0.5,1.0$, and $1.5 \mathrm{in}$.) and facesheet layups (quasi-isotropic tape, axially stiff tape, and fabric) for various imperfection amplitudes. 


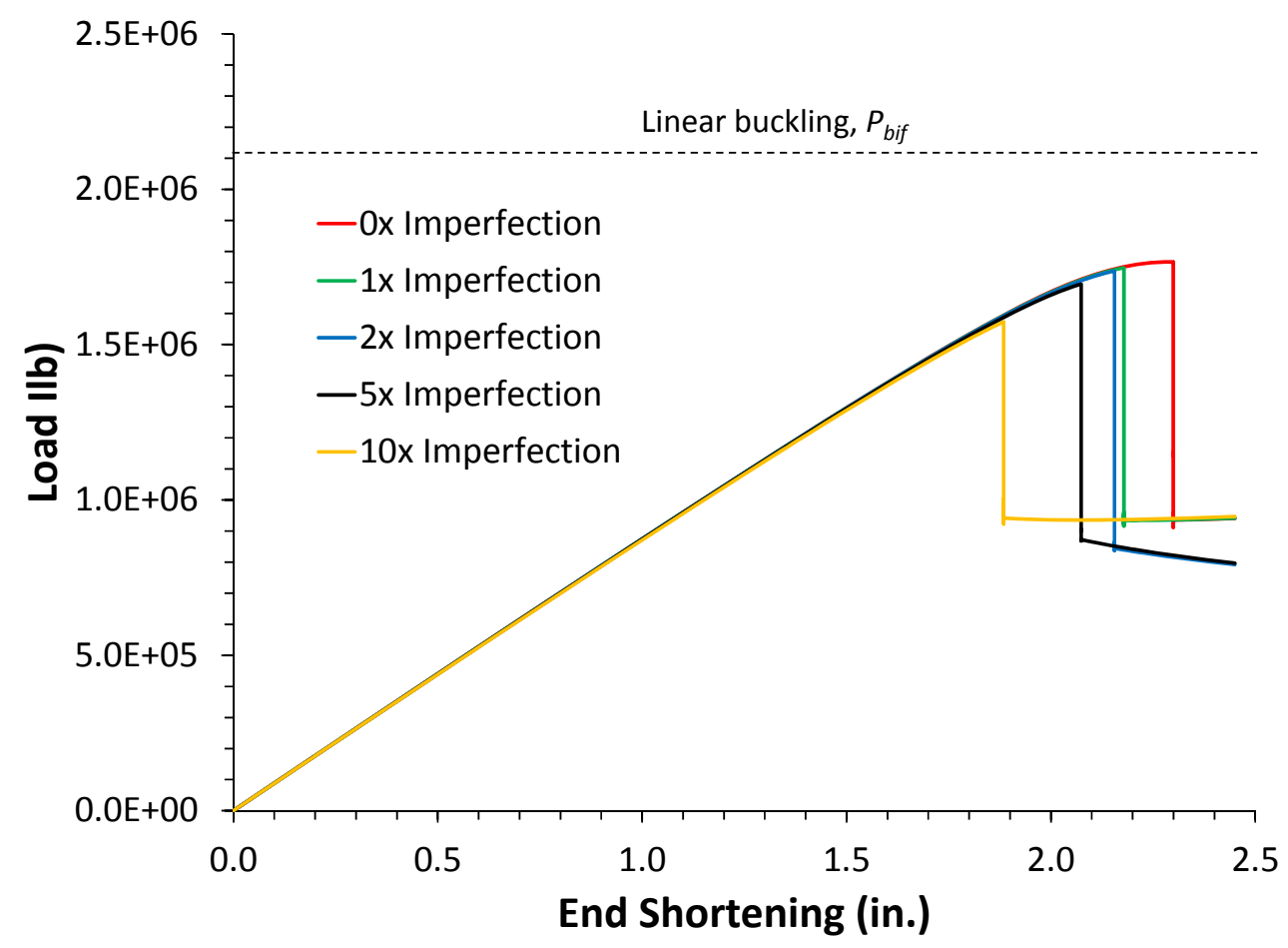

Figure 12. Buckling imperfection sensitivity study for representative full-height SLS PAF conical structures with 1.0-in. sandwich core and quasi-isotropic facesheet layup.

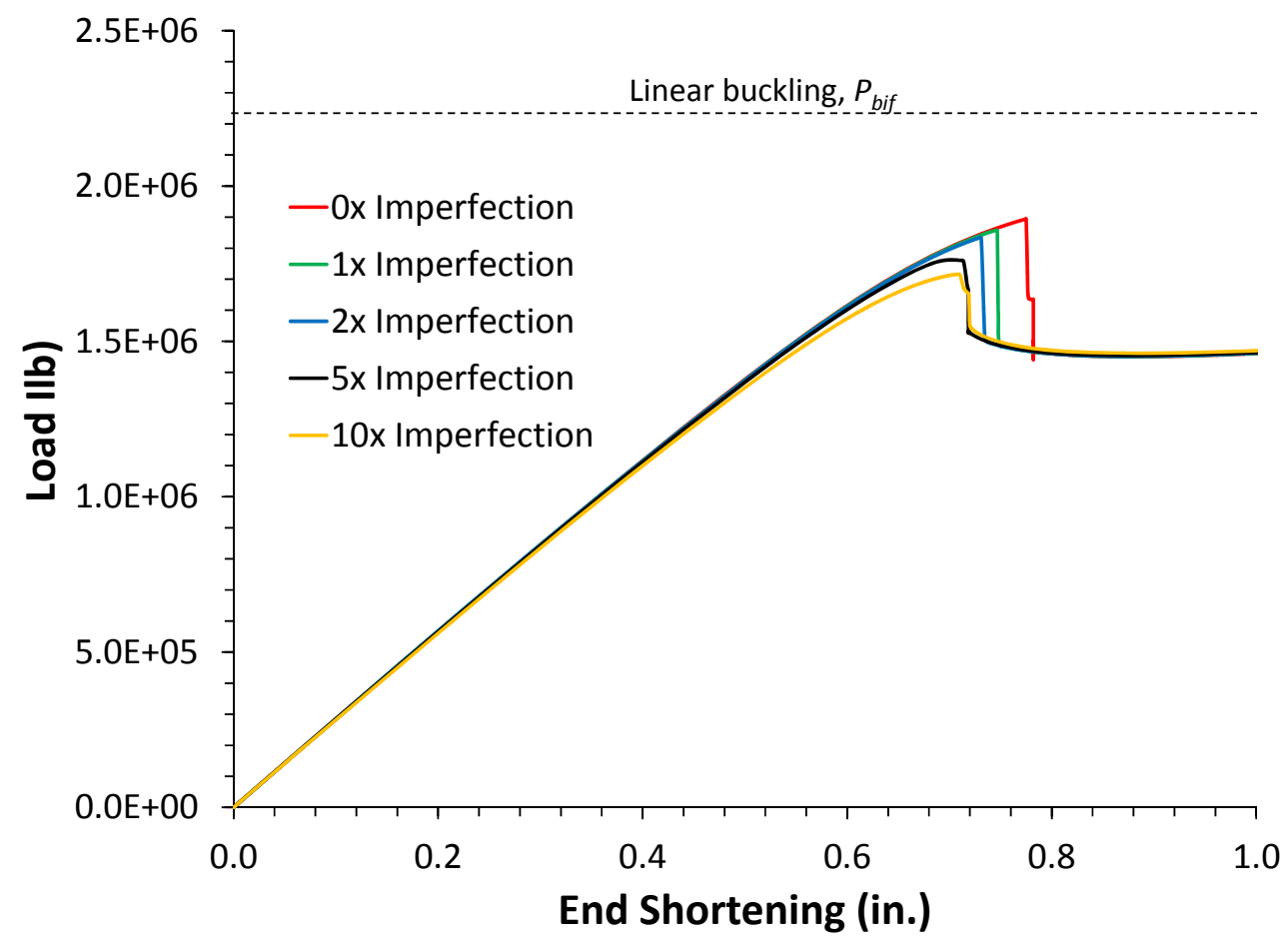

Figure 13. Buckling imperfection sensitivity study for representative half-height SLS PAF conical structures with 1.0-in. sandwich core and quasi-isotropic facesheet layup. 

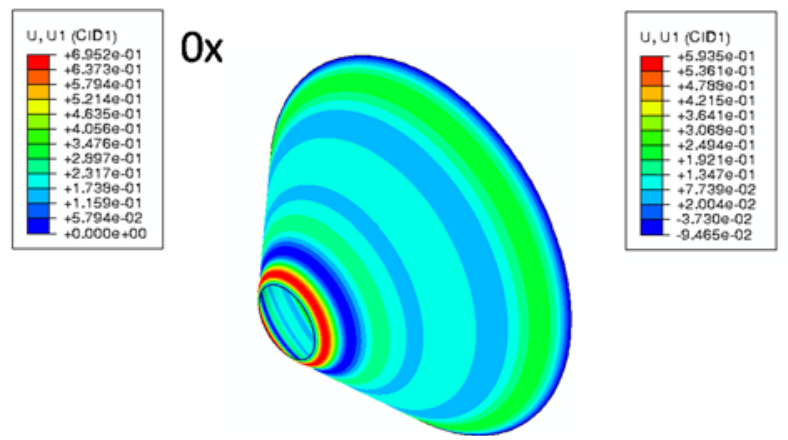

$1 x$
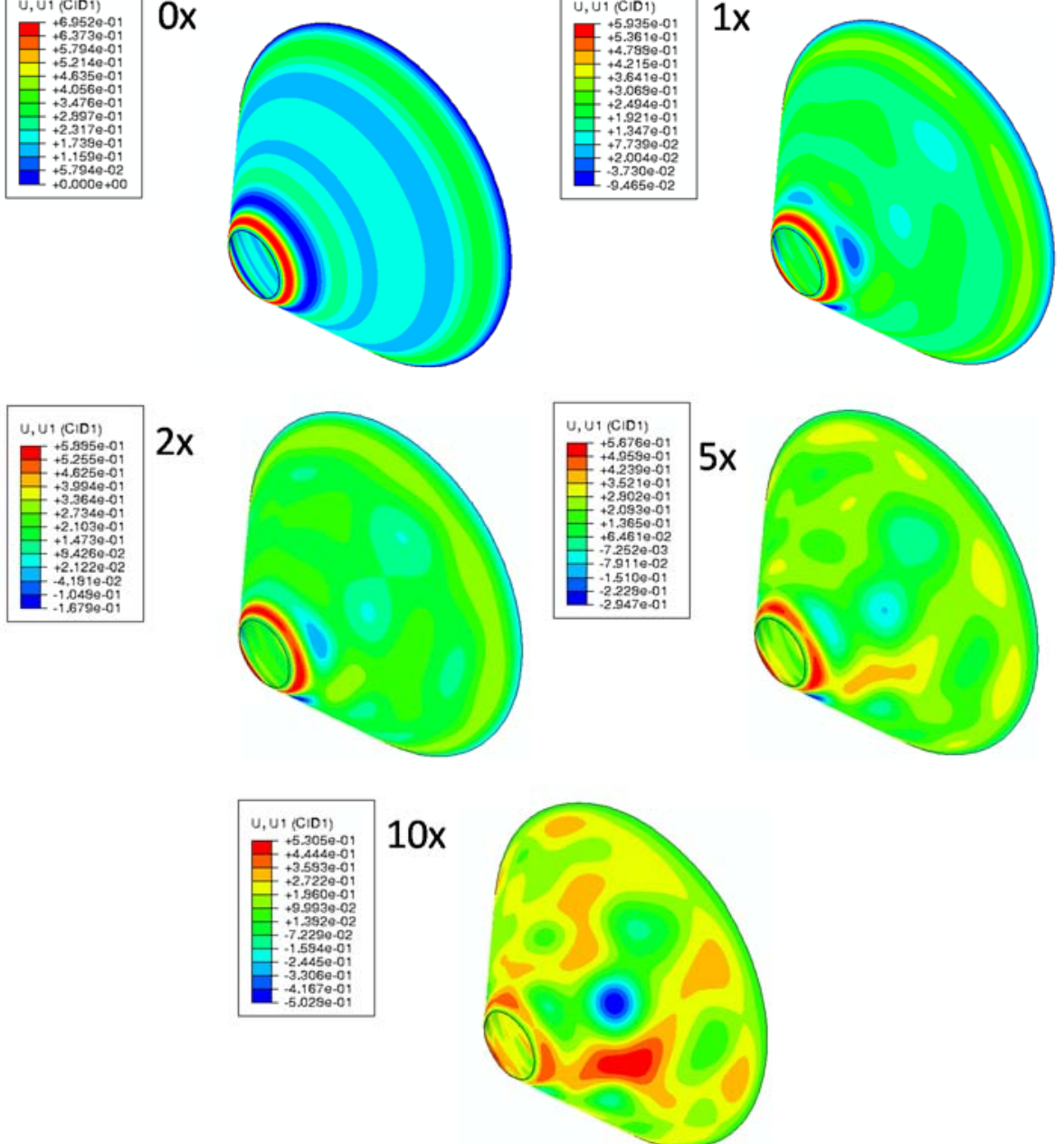

Figure 14. Radial deformation of representative SLS PAF full-height conical structures for various imperfection amplitudes with 1.0-in. sandwich core and quasi-isotropic facesheet layup. 

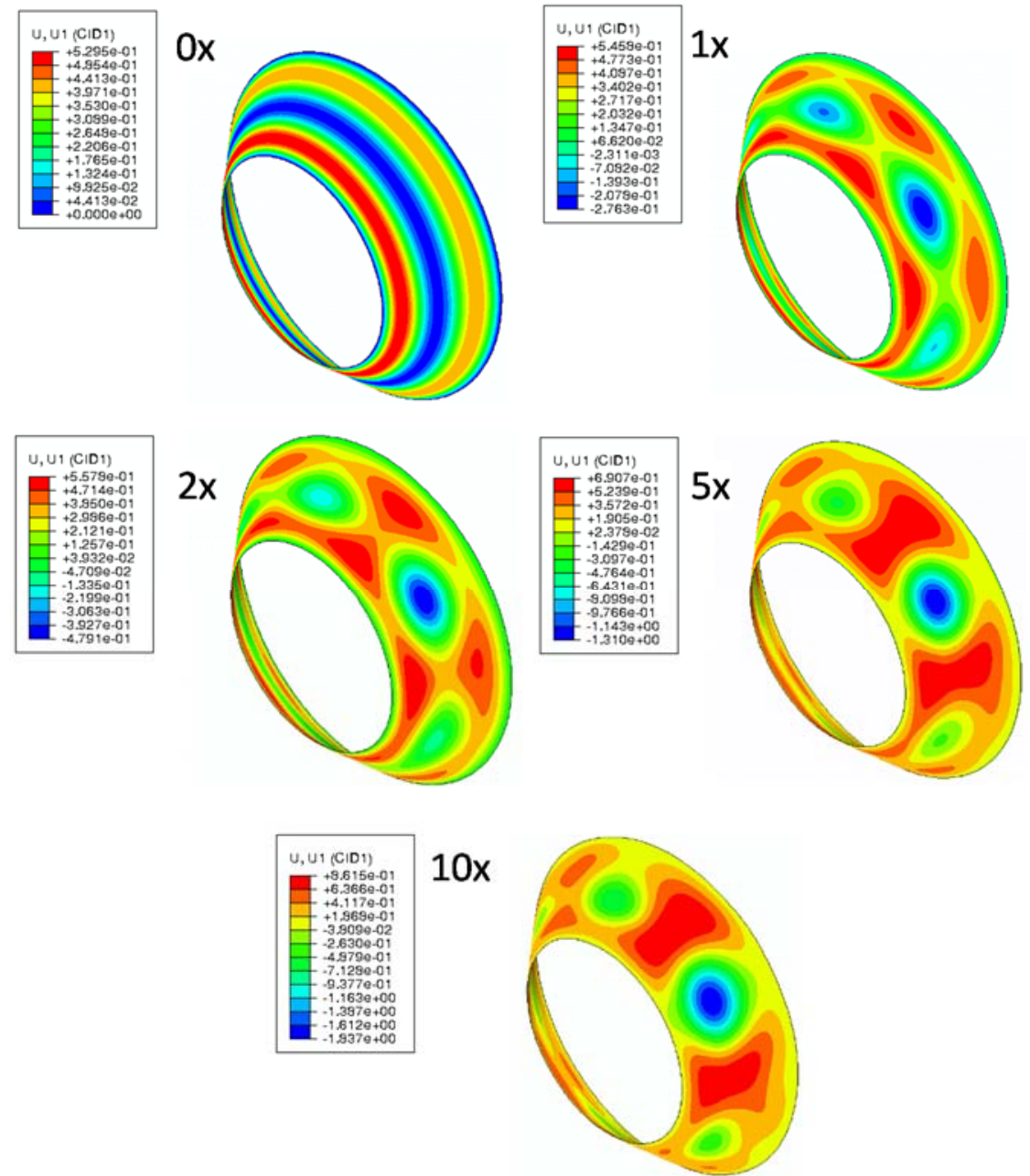

Figure 15. Radial deformation of representative SLS PAF half-height conical structures for various imperfection amplitudes with 1.0-in. sandwich core and quasi-isotropic facesheet layup. 

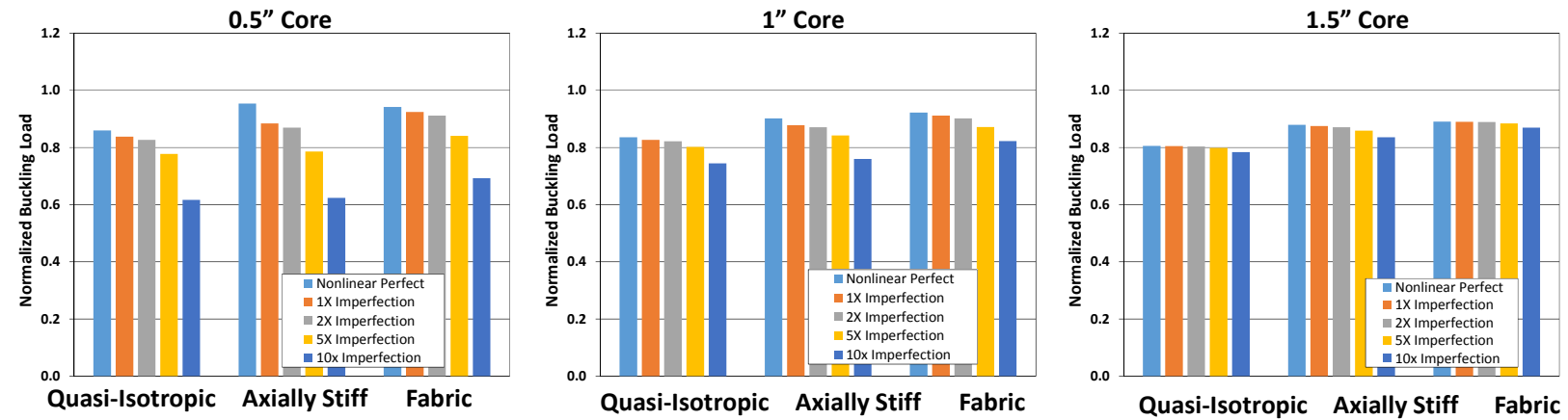

Figure 16. Normalized buckling loads of representative SLS PAF full-height conical structures for all sandwich core thicknesses (0.5, 1.0, and 1.5 in.) and facesheet layups (quasi-isotropic tape, axially stiff tape, and fabric) for various imperfection amplitudes.
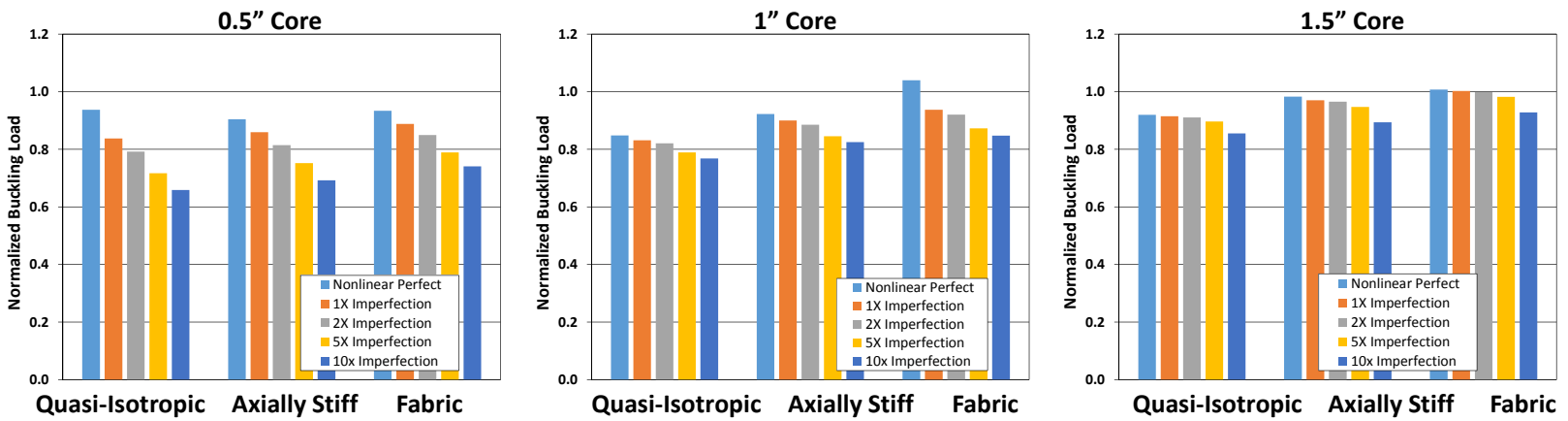

Figure 17. Normalized buckling loads of representative SLS PAF half-height conical structures for all sandwich core thicknesses (0.5, 1.0, and 1.5 in.) and facesheet layups (quasi-isotropic tape, axially stiff tape, and fabric) for various imperfection amplitudes.

-Quasi-Isotropic FS, 0.5 in Core - - Axially Stiff FS, 0.5 in Core

- -Quasi-Isotropic FS, 1 in Core - - -Axially Stiff FS, 1 in Core

- Quasi-Isotropic FS, 1.5 in Core - Axially Stiff FS, 1.5 in Core $\rightarrow$ Fabric FS, 0.5 in Core

- Fabric FS, 1 in Core

$\rightarrow$ Fabric FS, 1.5 in Core

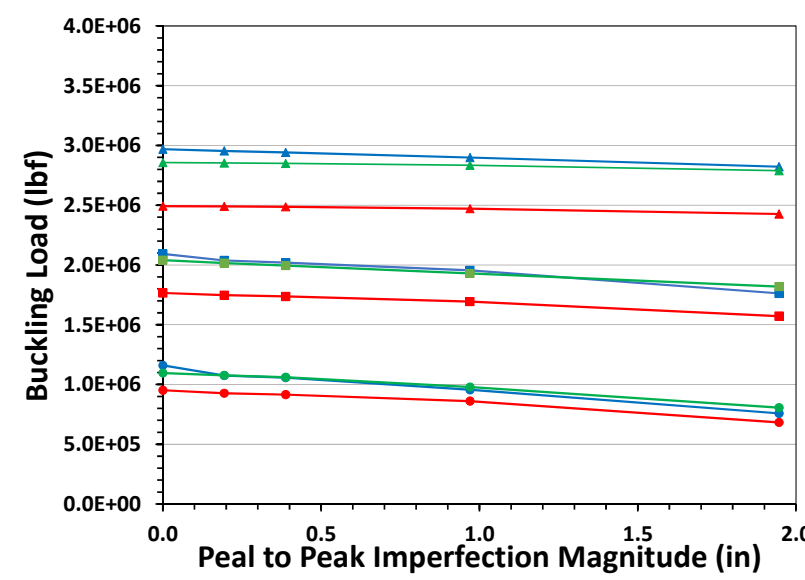

(a) Full-Height

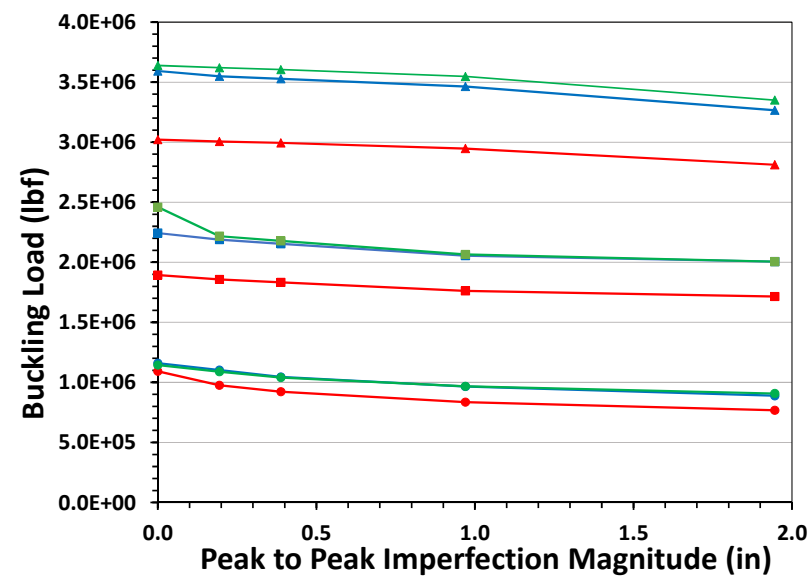

(b) Half-Height

Figure 18. Buckling load vs. peak-to-peak imperfection magnitude of representative SLS PAF full-height and half-height conical structures for all sandwich core thicknesses $(0.5,1.0$, and $1.5 \mathrm{in}$.) and facesheet layups (quasi-isotropic tape, axially stiff tape, and fabric) for various imperfection amplitudes. 